\title{
POLÍTICAS PÚBLICAS PARA A DIVERSIDADE
}

\author{
PUBLIC POLICIES FOR DIVERSITY
}

Nilma Lino Gomes*

\begin{abstract}
RESUMO:
A partir do século XXI, as mudanças tecnológicas, a aproximação das fronteiras via mundo virtual, as imigrações, as desigualdades, a globalização capitalista, os fundamentalismos, a luta pela terra e pela igualdade de direitos assumem outros contornos. Nesse processo, o termo diversidade começou a ser mais usado, no campo das políticas, para nomear as diferentes formas de "ser diferente", bem como os dilemas e avanços dessa questão no contexto das relações de poder. Este artigo apresenta e analisa as mudanças ocorridas no Estado brasileiro, a partir da implementação das políticas públicas para a diversidade, com ênfase nas ações do governo federal no período de 2003 a 2016. Discute o relevante papel das pressões e reivindicações dos movimentos sociais de caráter emancipatório e dos coletivos sociais diversos transformados em desiguais, nessa mudança. Adverte sobre o perigo de retrocesso dessas políticas devido ao atual momento histórico e político de avanço das forças conservadoras e do realinhamento da direita e do capitalismo no Brasil e em outros países do mundo.
\end{abstract}

PALAVRAS CHAVE: Políticas. Políticas públicas. Diversidade. Movimentos sociais. Emancipação social.

\section{ABSTRACT:}

From the twenty-first century, technological changes, the closeness of borders through the virtual world, immigration, inequalities, capitalist globalization, fundamentalism, the struggle for land and equal rights take on other forms. In this process the term diversity has become more widely used in the field of politics to name the different ways of being different, as well as the dilemmas and advances of this issue in the context of power relations. This article presents and analyzes the changes that have occurred in the Brazilian State, from the implementation of public policies for diversity, with emphasis on the actions of the federal government in the period from 2003 to 2016. It discusses the relevant role of the pressures and claims of social movements of emancipatory character and the various social collectives transformed into unequal, in this change. Warns about the danger of retrogression of these policies due to the current historical and political moment of advancement of the neoconservative forces and the realignment of the right and capitalism in Brazil and in other countries of the world.

KEY WORDS: Policies. Public policy. Diversity. Social movements. Social Emancipation

\footnotetext{
* Doutora em Antropologia Social (USP) e pós-doutora em Sociologia pela Universidade de Coimbra. Professora da graduação e pós-graduação da FAE/UFMG. Integrante da equipe do Programa Ações Afirmativas na UFMG e bolsista do CNPQ. Foi reitora pro-tempore da Universidade da Integração Internacional da Lusofonia Afrobrasileira (UNILAB) (2013-2014), ministra da Secretaria de Políticas de Promoção da Igualdade Racial (SEPPIR) e do Ministério das Mulheres, Igualdade Racial, Juventude e Direitos Humanos da presidenta legitimamente eleita Dilma Rousseff (2015-2016).

E-mail: nilmagomes@uol.com.br
} 
Há 20 anos atrás, a questão da diversidade não era discutida como um dos possíveis eixos das políticas públicas. Essa discussão podia ser encontrada nos debates políticos de entidades específicas dos movimentos sociais de caráter emancipatório, ou ainda, em algumas pesquisas acadêmicas.

Mais recentemente, no início do século XXI, é que o termo diversidade começa a ser mais usado, no campo das políticas, para nomear as diferentes formas de "ser diferente", os dilemas e avanços de sujeitos sociais pertencentes a coletivos sociais diversos transformados em desiguais, no contexto das relações de poder.

\section{O PROTAGONISMO DOS MOVIMENTOS SOCIAIS EMANCIPATÓRIOS NAS TRANSFORMAÇÕES SOCIAIS}

Estamos no século XXI, no qual as mudanças tecnológicas, a aproximação das fronteiras via mundo virtual, as imigrações, as desigualdades, a globalização capitalista, os fundamentalismos, a luta pela terra e pela igualdade de direitos assumem outros contornos. Também tomaram outros contornos, além das lutas sociais, a resistência às estratégias de exploração capitalista, ao racismo, ao machismo, à xenofobia, à LGBTfobia, ao fundamentalismo político e religioso, à intolerância religiosa nos mais diversos lugares do mundo.

A quebra e a aproximação das fronteiras via intensa vida on-line, as negociações entre os países desenvolvidos e os países emergentes não somente mudaram ou intensificaram o contato entre pessoas, ideologias, posturas políticas e governos. Aproximaram e fizeram circular visões de mundo, valores, sujeitos, conceitos, preconceitos, visões sobre o meio ambiente, sobre a sustentabilidade, sobre o compromisso social de cada um de nós com a vida em nosso planeta.

Quais seriam os motivos dessa mudança? Vários. Mas vamos nos concentrar nesse artigo no fato de que, principalmente nos últimos vinte anos, sujeitos sociais diversos passaram a ocupar um outro lugar de protagonismo social e político, organizados ou não em movimentos sociais. E quando se organizam, não o fazem vinculados a todo e qualquer movimento social, mas, sim, àqueles que levantam bandeiras emancipatórias de gênero, raça, idade, relação campo/cidade, deficiência.

Essa ideia de emancipação consiste em uma articulação de perspectivas que combinam desde a visão democrática-igualitarista de sociedade, a uma visão socialista e, até mesmo, 
revolucionária de acordo com o movimento social ou coletivo que a reivindica. Trata-se de algo complexo que, na minha opinião, ainda precisará ser mais estudado pelos campos da Ciência Política, Filosofia Política, Sociologia e Educação. Esses coletivos sociais diversos, organizados ou não em movimentos sociais, passaram a usar cada vez mais a tecnologia, a cultura digital, as redes sociais, a seu favor, para disseminar suas ideias, respaldar suas ações, pressionar o Estado e o mundo privado no processo de formação da agenda, formulação, tomada de decisão, implementação e avaliação de políticas públicas. E são responsáveis por uma inflexão no campo das políticas públicas. Eles reivindicaram e reivindicam políticas públicas voltadas para a diversidade.

Esses sujeitos sociais e políticos passaram a se comunicar mais entre si, nacional e internacionalmente. Eventos como o Fórum Social Mundial aproximaram esses coletivos sociais diversos e os movimentos sociais de caráter emancipatório dos governos de esquerda, proporcionando a discussão de alternativas conjuntas para o enfrentamento da onde conservadora, do capitalismo exacerbado e do colonialismo incrustados em nossas estruturas sociais, políticas, econômicas e mentais.

Tudo isso faz com que compreendamos que o mundo não somente é desigual, mas também é diverso. E como a diversidade pode ser transformada em inferioridade e tratada de forma desigual no contexto das relações, disputas de poder e do jogo de interesses diversos. Também nos ajuda a refletir como a experiência social do mundo é muito maior do que a nossa experiência individual do mundo, como diz Santos (2009). Somos, hoje, quer queiramos ou não, obrigados a ver o outro, o diferente, não somente na sua diferença, mas, principalmente, reivindicando o direito à sua diferença e ao mesmo tempo a igualdade de direitos, aos direitos humanos.

Essa efervescência social e mundial caminha lado a lado com a exploração capitalista do mundo, com a ganância do capital financeiro, com a usurpação das terras e territórios dos povos tradicionais, com a corrupção, com os efeitos da mídia hegemônica e os impactos na produção do conhecimento em todas as áreas.

Somos desafiados a fazer outras perguntas quando estudamos as desigualdades em nosso país e no mundo. Perguntas que antes eram vistas como próprias dos movimentos sociais de caráter emancipatório, atualmente fazem parte tanto do mundo do cientista e do técnico quanto dos formuladores de políticas, do mundo político, jurídico, do legislativo e privado. 
A relação entre políticas públicas e diversidade está no cerne das mudanças do mundo. A onda imigratória enfrentada pela Europa, América Latina, América do Norte e outras regiões do mundo, fruto da busca por sobrevivência e dignidade daqueles que perderam tudo por causa da guerra, dos governos autoritários, do terrorismo, do fundamentalismo e do capitalismo exacerbado, colocam questões ligadas ao direito à diversidade para os Estados, os governos e suas políticas.

Apesar de alguns Estados e governos responderem a esse processo com medidas conservadoras e segregacionistas, outros começam a se questionar sobre o que fazer diante de tal fatalidade do mundo à luz dos direitos humanos. A questão das políticas para a diversidade assume um lugar de responsabilidade social e política não somente das cidadãs e cidadãos comuns, mas dos governos e das políticas públicas. E ela vem tensionando cada vez mais não só o setor público mas, também, o mercado e o mundo privado.

Nos últimos anos, quando o debate sobre a diversidade passa a ocupar mais espaço acadêmico e político, começamos a nos colocar questões diferentes: democracia, direito e diversidade; sustentabilidade e produção das diferenças; desigualdades e diversidade; povos ribeirinhos, das florestas, do campo, geraizeiros, quilombolas, ciganos, indígenas e o mundo da produção; lucro, igualdade e diversidade; sustentabilidade e compromisso social das empresas; mudanças climáticas, pobreza, fome; mundo da produção; terra, território e propriedade privada.

Essas questões que hoje se tornam preocupações sociais, políticas e acadêmicas em vários lugares do mundo tensionam o campo das políticas públicas e do conhecimento. Elas não vieram de um movimento do Estado para a sociedade mais ampla. Antes, vieram das pressões sociais e políticas organizadas pelos movimentos sociais, sindicatos e coletivos culturais, bem como pelos coletivos sociais diversos tratados como desiguais. Essa situação impõe uma nova dinâmica no mundo, no campo do conhecimento, na organização do Estado e no mundo privado.

Os movimentos sociais emancipatórios e os coletivos sociais diversos transformados em desiguais cada vez mais tomam consciência dos seus direitos não somente individuais, mas também coletivos. Compreendem que a exploração capitalista não se dá somente na fábrica, no mundo das ações e investimentos mas, também, nos mais diversos espaço-tempo e setores da vida social e cultural. E com isso, realizam uma inflexão na sua forma de exigir e lutar por direitos. O direito à diversidade é um deles. 
Esses sujeitos sociais e políticos constroem a narrativa e a reivindicação de que as suas lutas, desigualdades e diferenças devem ser objeto de políticas públicas. Não basta ao Estado, enquanto instituição política, jurídica e administrativa, e aos governos, enquanto a esfera pública responsável por administrá-lo, desenvolverem políticas sociais, de combate à pobreza, à fome, ao desemprego. Eles precisam considerar que o trato desigual e inferiorizante dado à diversidade acentua a situação de desigualdade para determinados coletivos sociais, colocando-os em uma situação ainda mais precária no mundo das grandes desigualdades. Estas incidem de maneira mais ou menos perversa não somente devido à situação de pobreza, de desemprego, de localização geográfica e regional. Elas pesam ainda mais de acordo com o pertencimento étnico-racial, o gênero, a sexualidade, a idade, a deficiência.

Com a ascensão de governos mais à esquerda em diferentes lugares do mundo no final do século XX e início do século XXI, assistimos a uma mudança interessante: alguns desses movimentos e coletivos sociais diversos - mesmo em pequena quantidade - conseguiram inserir alguns de seus representantes nos governos e espaços acadêmicos e da produção de conhecimento. E levaram para esses lugares a diversidade não somente na sua presença quantitativa, mas na sua concepção de política, na sua corporeidade e na sua história. Ou seja, o seu jeito de ser no mundo também passou a fazer parte da formulação e interpretação das políticas. As pressões sociais históricas desenvolvidas por esses movimentos e coletivos se somaram às bandeiras mais à esquerda, construindo alianças e compromissos. Um deles foi o compromisso de se construírem políticas públicas voltadas para a diversidade.

Embora o projeto de inserção como quadros nas estruturas do Estado (por exemplo, ministérios específicos para temas da diversidade e com orçamento específico) e nos governos (gestoras, gestores, cargos de confiança e da administração burocrática) ainda tenha sido de forma subalterna, os movimentos sociais e coletivos sociais diversos conseguiram que algumas das suas temáticas históricas se transformassem em políticas públicas nas esferas federal, estadual, municipal e distrital. Com formas, níveis, condições orçamentárias e lugar de poder distintos, dependendo das forças políticas, partidárias e da forma como tais políticas foram desenvolvidas, uma coisa é certa: algumas das temáticas da diversidade se transformaram em políticas de Estado no combate ao racismo, ao sexismo, ao machismo, a LGBTfobia, bem como a maior garantia dos direitos das crianças e adolescentes, jovens e idosos. 


\section{O BRASIL E AS POLÍTICAS PÚBLICAS PARA A DIVERSIDADE}

De acordo com Souza (2006), os debates sobre políticas públicas implicam responder à questão sobre o espaço que cabe aos governos na definição e implementação de políticas públicas. A autora não partilha da ideia de que o Estado (ou os governos que decidem e implementam políticas públicas ou outras instituições que participam do processo decisório) reflete tão-somente as pressões dos grupos de interesses e dos movimentos sociais. Segundo ela, essa seria a versão mais simplificada do pluralismo. A autora também não defende que o Estado opta sempre por políticas definidas exclusivamente por aqueles que estão no poder. Essa, segundo ela, seria fruto de versões simplificadas do elitismo. E nem tampouco advoga que servem apenas aos interesses de determinadas classes sociais, como afirmam as concepções estruturalistas e funcionalistas do Estado.

A tendência da autora é concordar com a interpretação de que:

no processo de definição de políticas públicas, sociedades e Estados complexos como os constituídos no mundo moderno estão mais próximos da perspectiva teórica daqueles que defendem que existe uma "autonomia relativa do Estado", o que faz com que o mesmo tenha um espaço próprio de atuação, embora permeável a influências externas e internas (Evans, Rueschmeyer e Skocpol, 1985). Essa autonomia relativa gera determinadas capacidades, as quais, por sua vez, criam as condições para a implementação de objetivos de políticas públicas. A margem dessa "autonomia" e o desenvolvimento dessas "capacidades" dependem, obviamente, de muitos fatores e dos diferentes momentos históricos de cada país. (SOUZA, 2006, p. 27).

Embora reconheça que na formulação, implementação e análise das políticas públicas possa ser reservado ao Estado essa "autonomia relativa", partilho da ideia de que as políticas públicas voltadas para a diversidade implementadas pelo Brasil, nos últimos anos, são resultado muito mais das pressões dos movimentos sociais emancipatórios e coletivos sociais diversos, o que não chega a ser um pluralismo político.

Ressalto que assistimos, nos últimos anos, um outro tipo de pressão sobre o Estado e demais instituições na formulação, implementação e avaliação de políticas. Os movimentos sociais de caráter emancipatório e os coletivos sociais diversos exigem do Estado e dos governos que eles direcionem parte das suas políticas não somente para um determinado setor ou grupo étnico, racial e social específico, simplesmente pelo fato de serem considerados e se considerarem diferentes. Eles demandam que o direito à diversidade seja parte intrínseca do conjunto das políticas públicas, quer sejam elas universais ou específicas. Demandam que as 
questões da diversidade e a forma desigual como esta tem sido tratada deverão receber especial atenção por parte do Estado e dos governos, principalmente nas sociedades pluriculturais, pluriétnicas e plurirraciais, a fim de se corrigirem mais rapidamente desigualdades históricas. Desigualdades estas que recaem com mais contundência e violência sobre determinados coletivos sociais devido ao fato de a sua diferença - no contexto das relações de poder e econômicas - ser considerada como inferioridade. São os coletivos atingidos e impedidos de construir uma caminhada de igualdade, cidadania e justiça social na nossa complexa democracia.

Encaixar as políticas voltadas especificamente para esses coletivos desenvolvidas nos últimos treze anos, em nível federal, estadual, municipal e distrital, no Brasil, no conjunto das políticas redistributivas não traduz toda a sua complexidade e nem comporta a dimensão afirmativa que elas possuem. Estamos diante de um fenômeno mais complexo.

As políticas públicas para a diversidade podem transversalizar as demais políticas e, ao mesmo tempo, serem formuladas e implementadas de forma afirmativa, por determinado tempo, a fim de corrigir desigualdades históricas que incidem sobre determinados coletivos sociais marcados por uma diferença reconhecida social e politicamente. Há ainda o reconhecimento público de que essa diferença tem sido tratada de forma desigual pelo Estado e demais instituições da sociedade. Sendo assim, essas políticas públicas colocam em xeque e questionam até onde vai a "autonomia do Estado". Desvelam que o trato dado à diversidade no campo das políticas públicas revela uma postura de neutralidade estatal (e, em alguns casos, de negação estatal) em relação a tensão diversidade/desigualdade.

As demandas e as lutas por emancipação social e reconhecimento da diversidade, hoje, no Brasil, extrapolam a esfera do Estado. Começam a indagar e a tensionar, também, uma parte do mundo capitalista que sempre fingiu não se importar com a relação desigualdade e diversidade. Há um movimento de pressão para que as políticas públicas e o mercado se abram à diversidade e a reconheçam não só como algo próprio do acontecer humano, mas como um direito. É a força dos movimentos sociais emancipatórios e dos coletivos sociais considerados diversos e tratados como desiguais incidindo sobre a sociedade.

Paralelamente às políticas e preocupações do Estado, os movimentos sociais continuam com o seu trabalho de denúncia às violações de direitos, discriminações, preconceitos e ainda passam a exercer maior controle público das políticas construídas pelo Estado para atender esses mesmos direitos. 
Um cenário ainda bem mais complexo no campo das políticas públicas vem se desenhando. Por isso, assistimos nesses últimos vinte anos, a um movimento das estruturas internas do Estado na implementação de políticas de ações afirmativas e não somente de políticas universais. Com todos os desafios possíveis, a diversidade passa a ocupar um outro lugar no campo das políticas a ponto de podermos dizer que o país passou a implementar políticas públicas para a diversidade. $\mathrm{O}$ fato de ter implementado não retira os conflitos, os limites e as contradições na formulação e implementação de tais políticas.

O grande desafio e que ainda não foi concluído é que os sujeitos dessas políticas pudessem ser não somente os seus destinatários, mas, principalmente, sujeitos na construção da agenda e na formulação dessas mesmas políticas. Ainda nos falta institucionalizar políticas para a diversidade que sejam construídas com os sujeitos diversos e não somente para os sujeitos diversos. E isso só poderá ser alcançado com uma intensa participação social.

Nos governos Lula e Dilma, bem como nos governos mais à esquerda que se instauraram no mundo no mesmo período, a participação social foi mais estimulada. Quer seja de uma maneira mais ampla através do exercício do direito ao voto ou da participação nos conselhos com representação da sociedade civil e do governo, houve lugar para a escuta de demandas históricas ainda não contempladas no campo das políticas. Esse processo desencadeou, no Brasil, a realização de diversas conferências estaduais, nacionais, municipais e distrital com temas específicos voltados para a diversidade: igualdade racial, mulheres, indígenas, direitos humanos, direitos da população LGBT, idosos, crianças e adolescentes, juventude, pessoas com deficiência, entre outras.

Juntamente com a realização das conferências com as temáticas convencionais no campo das políticas públicas, tais como: educação, saúde, assistência social, as conferências voltadas para os temas de diversidade e a forma como estas se concretizaram na garantia de direitos aos coletivos sociais diversos e transformados em desiguais, contribuíram para conferir se o Estado implementava ou não as políticas para a diversidade, quantos recursos orçamentários eram investidos, qual a capilaridade desse tema no planejamento dos governos, como as diversas temáticas foram descentralizadas em nível estadual, municipal e distrital e se as principais demandas dos movimentos sociais emancipatórios e dos coletivos sociais diversos estavam ou não sendo atendidas.

Esses últimos vinte anos foram anos de muitos desafios, tensões, debates, mas, também, da produção de um olhar afirmativo vindo do Estado e suas políticas para o trato desigual dado à diversidade em nosso país. E mais, o trato desigual dado aos sujeitos 
pertencentes a esses coletivos sociais diversos. Cabe destacar o importante papel das pesquisas institucionais e acadêmicas que investiram na compreensão da relação desigualdade e diversidade para uma melhor compreensão desse quadro.

Essa inflexão do Estado em relação à diversidade não significou esmorecimento na implentação das outras políticas sociais de caráter universal. Estas continuaram a ser o carrochefe das políticas. Porém, mesmo que não fosse com a mesma força e centralidade, as políticas para a diversidade caminharam de forma paralela e tentando se tornar realmente transversais.

O lugar dessas políticas consideradas transversais na estrutura do Estado ainda carece de melhor definição. Mesmo tendo existido nos últimos treze anos, no governo federal, estadual, municipal e distrital, ministérios e secretarias específicos denominados transversais (mulher, igualdade racial, deficiência, juventude, direitos humanos), essa especificidade ainda tem muito que caminhar no campo da organização do Estado e das suas políticas.

Ser transversal é mais do que ter uma temática específica sendo olhada ou observada de forma especial no conjunto das políticas públicas. Significa que, além do conjunto das políticas convencionais deve-se reconhecer o trato desigual e inferiorizante dado à diversidade ao longo do nosso contexto histórico, social, político e econômico. Esse mesmo trato acabou contribuindo para que as desigualdades juntamente com as discriminações e preconceitos acarretassem uma situação ainda mais negativa para certos coletivos sociais considerados diversos pela sociedade. Os sujeitos pertencentes a esses coletivos participam muito menos da garantia dos direitos democráticos quando comparados com o conjunto da população.

Por mais que o Estado invista em políticas públicas de maneira universal para toda a população, negros, quilombolas, indígenas, mulheres, população LGBT, pessoas do campo, pessoas com deficiência, crianças, jovens, idosos, e principalmente os pobres ainda se encontram em situação de maior desvantagem devido ao trato desigual dado à sua diferença.

Por isso é necessário reeducar o Estado e os governos para a diversidade. Reeducá-los para compreender que a diversidade é muito mais do que a soma das diferenças ou dos diferentes. Ela é uma construção social, histórica, cultural, política e econômica das diferenças que se realiza no contexto das relações de poder. Os coletivos sociais diversos participam da disputa por hegemonia que constituem o campo das políticas, na maioria das vezes, organizados em movimentos sociais de caráter emancipatório. E, ao longo dos anos, mesmo que ainda de maneira tímida perto da gravidade da situação, algumas mudanças vêm surgindo em nível federal, estadual, municipal e distrital. 


\section{PARA REFLETIR: DOIS EXEMPLOS DE POLÍTICAS PÚBLICAS PARA A DIVERSIDADE}

Para exemplificar como se materializou a implementação de políticas para a diversidade ao longo dos últimos 13 anos pelo governo federal (em articulação com o legislativo e o judiciário), descreveremos algumas políticas, programas e ações que hoje fazem parte do campo das políticas públicas para a diversidade, no Brasil. Tais políticas resultaram em desdobramentos semelhantes nos estados, municípios e DF.

Destacaremos, a título de exemplo, as políticas de igualdade racial e de gênero.

\subsection{Igualdade racial}

- Plano Juventude Viva - lançado em setembro de 2012, iniciativa que articula ações de onze Ministérios, de Governos Estaduais e Municipais para reduzir a vulnerabilidade de jovens negros a situações de violência física e simbólica.

- Programa Brasil Quilombola - coordenado pela então Secretaria de Políticas de Promoção da Igualdade Racial (SEPPIR), foi lançado em 12 de março de 2004 com o objetivo de integrar ações voltadas à melhoria das condições de vida e ampliação do acesso a bens e serviços públicos das pessoas que vivem em comunidades quilombolas no Brasil.

- Em 20 de novembro de 2007 foi instituída a Agenda Social Quilombola através do Decreto 6.261. A Agenda funciona por meio de um Comitê composto por representantes de onze órgãos federais e sociedade civil. Tem como objetivo garantir o acesso a terra, inclusão produtiva, infraestrutura, qualidade de vida e direito e cidadania a essas comunidades.

- Lei 10.639/03 - altera a LDB 9394/96 e torna obrigatório o ensino de História e Cultura Afro-brasileira e Africana nas escolas de ensino fundamental e médio, regulamentada pelo Parecer CNE/CP 03/2004 e Resolução CNE/CP 01/2004.

- Decreto 4887/03 - regulamenta o procedimento para identificação, reconhecimento, delimitação, demarcação e titulação das terras ocupadas por remanescentes das comunidades quilombolas de que trata o art. 68 do Ato das Disposições Constitucionais Transitórias. 
- Conferências Nacionais de Promoção da Igualdade Racial - CONAPIR (2005, 2009 e 2013).

- Conselho Nacional de Promoção da Igualdade Racial - CINAPIR criado pela Lei 10.678 (23/05/2003), e regulamentado pelo Decreto 4.885 (20/11/2003), com alterações feitas pelo Decreto 6.509 (16/07/2008).

- Decreto $\mathrm{n}^{\mathrm{o}}$ 6.040/2007, que institui a Política Nacional de Desenvolvimento Sustentável dos Povos e Comunidades Tradicionais.

- Lei 12.288/2010 - Estatuto da Igualdade Racial.

- Diretrizes curriculares nacionais para a Educação Escolar Quilombola - Parecer CNE/CEB 16/2012 e Resolução CNE/ CEB 08/2012.

- Lei $\mathrm{n}^{\mathrm{o}}$ 12.711, de agosto de 2012 - cotas nas Universidades e nos Institutos Técnicos Federais - essa lei começou a ser implementada pelo Ministério da Educação (MEC) no ano seguinte à sua aprovação.

- Decreto 8.136/2013 - Sistema Nacional de Promoção da Igualdade Racial - SINAPIR -, instituído pelo Estatuto da Igualdade Racial (Lei 12.288/2010). Tem como objetivo criar a sinergia entre governo federal, estadual, municipal e distrital na elaboração, fortalecimento e implementação de políticas de igualdade racial no Brasil.

- Guia de Políticas Públicas para os povos ciganos - Brasil Cigano (2013). (É importante citar o guia pois este tinha o objetivo de construir o Plano Nacional de Políticas para os Povos Ciganos, cujas diretrizes foram planejadas ainda na SEPPIR durante a gestão da então presidenta Dilma Rousseff).

- A Lei $\mathrm{n}^{\mathrm{0}} 12.990$, de 9 de junho de 2014 - reserva de vagas para candidatos(as) negros(as) em concursos públicos federais. Destina 20\% das vagas para negros nos concursos para cargos efetivos e empregos públicos no âmbito da Administração Federal Direta e Indireta (Essa lei foi aprovada como constitucional em 08/06/17, por unanimidade, pelo Supremo Tribunal Federal, em resposta a ação movida pela Ordem dos Advogados do Brasil (OAB)).

- Resolução 746/2015: estabelece o preenchimento obrigatório do campo cor ou raça em todas as contratações feitas por programas que foram financiados pelo Fundo de Amparo ao Trabalhador, o que possibilitará a construção de programas específicos de equidade racial no mundo do trabalho.

- Criação da Reunião de Autoridades sobre os Direitos dos Afrodescendentes, no âmbito do Mercosul - RAFRO, em 2015. A criação da RAFRO era uma demanda da 
Comissão Permanente Discriminação, Racismo e Xenofobia da Reunião de Altas Autoridades em Direitos Humanos e Chancelarias (RAADH), coordenada no Brasil pela SEPPIR e tem importância internacional na construção de políticas de igualdade racial nos países do Mercosul.

\subsection{Igualdade de gênero}

- Política nacional de enfrentamento à violência contra as mulheres.

- Pacto nacional pelo enfrentamento à violência contra as mulheres.

- Casa da Mulher Brasileira. Uma inovação no atendimento humanizado às mulheres. Integra no mesmo espaço serviços especializados para os mais diversos tipos de violência contra as mulheres: acolhimento e triagem; apoio psicossocial; delegacia; Juizado; Ministério Público, Defensoria Pública; promoção de autonomia econômica; cuidado das crianças - brinquedoteca; alojamento de passagem e central de transportes.

- Ampliação da Central de Atendimento à Mulher - Ligue 180.

- Organização e humanização do atendimento às vítimas de violência sexual (Decreto n. 7.958 de 13 de março de 2013; Portaria Interministerial n ${ }^{\circ} 288$ de 25 de março de 2015 (SPM/PR, MJ, MS); e a Norma Técnica de Atenção Humanizada às Pessoas em Situação de Violência Sexual com Registro de Informações e Coleta de Vestígios).

- Centros de Atendimento às Mulheres nas regiões de fronteira seca.

- Conselho Nacional dos Direitos da Mulher (CNDM).

- Conferência Nacional de Políticas para as Mulheres (CNPM).

- Unidades Móveis (ônibus e barcos especialmente adaptados para atendimento das mulheres) .

- Lei $n^{\circ} 11.340 / 2006$ - popularmente conhecida como Lei Maria da Penha - tornou-se o principal instrumento legal para coibir e punir a violência doméstica praticada contra mulheres no Brasil. Em 2012, foi considerada pela Organização das Nações Unidas $(\mathrm{ONU})$, a $3^{\mathrm{a}}$ melhor lei do mundo no combate à violência doméstica, perdendo apenas para Espanha e Chile.

- Lei $\mathrm{n}^{\mathrm{o}}$ 13.104/2015 - a Lei do Feminicídio. A Lei alterou o código penal para incluir mais uma modalidade de homicídio qualificado, o feminicídio, a saber, crime de ódio baseado no gênero. 
De forma mais geral, salientamos também outras políticas públicas para a diversidade tais como: Estatuto do Idoso (Lei $\mathrm{n}^{\mathrm{o}} 10.741$ de 2003), Estatuto da Juventude (Lei no 12.852/2013), Estatuto da pessoa com deficiência (Lei $n^{\circ} 13.146 / 2015$, que instituiu a Lei de Inclusão da Pessoa com Deficiência). Cabe destacar os conselhos e as conferências nacionais de Direitos Humanos, Pessoa com Deficiência, Criança e Adolescente, Idosos, LGBT.

Esses exemplos pretendem demonstrar como o governo federal (em articulação com o legislativo e o judiciário), de 2003 a maio de 2016, passou a incorporar as demandas dos movimentos sociais emancipatórios e dos coletivos sociais diversos no campo das políticas públicas. E como estas se transformaram em políticas de Estado sendo, inclusive, institucionalizadas na forma de lei, com estrutura, orçamento, programas e ações próprias.

\section{CONCLUINDO}

As políticas para a diversidade provocaram mudanças em nosso país. Mudanças no campo dos direitos, na concepção, construção e implementação de políticas, na disputa orçamentária e no imaginário social sobre os coletivos diversos tratados como desiguais e o seu direito a uma política que articule superação das desigualdades, equidade e justiça social.

Temas como combate ao racismo, a LGBTfobia e ao machismo, garantia do direito das crianças e adolescentes, dos jovens e dos idosos como dever do Estado e da sociedade passaram a ocupar outro lugar na agenda política, na arena jurídica, nas leis, na produção do conhecimento e nas políticas de distribuição de renda.

Embora possamos argumentar que os impactos das políticas para a diversidade ainda sejam poucos diante da imbricada e tensa relação entre garantia dos direitos, superação das desigualdades e reconhecimento à diversidade, é certo que mudanças sobre o tema foram realizadas em nosso país.

O tema da diversidade como um dos eixos orientadores das políticas universais, bem como uma política pública específica deixou de ser somente reivindicação dos movimentos sociais e seus ativistas, e passou a ocupar um lugar nas preocupações políticas, na produção acadêmica, nos debates do legislativo, nos meios jurídicos.

Essas mudanças produzem reações. Assistimos, a partir de maio de 2016, uma ofensiva das forças conservadoras e capitalistas no Brasil. Ofensiva que se dá na Europa, América Latina, África. E que se concretiza em novas formas de golpe de Estado, de retirada 
de direitos, de violência midiática e policial, de violência no campo e contra os povos indígenas e quilombolas.

A intensidade da ofensiva conservadora no mundo é proporcional ao tanto que as lutas sociais conseguiram abalar as fortes estruturas do capitalismo e do colonialismo que ainda perduram em nosso imaginário, políticas e práticas.

Quais os desafios esse processo efervescente de retrocesso nos traz? Além da luta pela retomada da democracia, faz-se necessária a reação popular diante das reformas promovidas pelo Executivo que assumiu o poder, a partir de maio de 2016, após o impeachment da presidenta legitimamente eleita Dilma Rousseff, apoiado pela ala conservadora do legislativo e do judiciário. Tais reformas, acompanhadas das medidas de austeridade fiscal impostas pelos setores capitalistas aos diversos países do mundo, certamente, farão retroceder direitos conquistados e garantidos pelas trabalhadoras e pelos trabalhadores desde a década de 30 do século XX. Os movimentos sociais e os coletivos sociais diversos transformados em desiguais não podem desistir dessa luta (GOMES, 2016).

Não há políticas públicas para a diversidade sem democracia, assim como não há democracia sem políticas públicas para a diversidade. Para que essas políticas duramente conquistadas possam avançar e não sofram ainda mais retrocessos do que já vêm sofrendo, a partir de maio de 2016, é necessário que o país retome a normalidade democrática.

E retomar a normalidade democrática significa reafirmar o direito do voto na escolha do(a) presidente(a) e demais representantes do país e continuar lutando pela garantia dos direitos humanos, sociais, políticos, coletivos e econômicos. No caso das políticas para a diversidade, significa tensionar para que elas não se percam dentro das políticas universais. Significa, também, continuar a luta por mais políticas de ações afirmativas. Estas últimas assumiram um papel central no conjunto das políticas públicas para a diversidade desenvolvidas pelo Brasil nos últimos treze anos. Atuaram como forma radical de correção das desigualdades e de construção de justiça social aos coletivos sociais com histórico de exclusão e discriminação em função do gênero, da raça, da etnia, da sexualidade, da nacionalidade, principalmente, por meio da modalidade das cotas.

A diversidade escancara a face oculta das relações de poder e da desigualdade na sociedade e no campo das políticas. Essa face conservadora, preconceituosa, arrogante, autoritária que muitas vezes disfarçamos e relutamos aceitar que ela existe. Perturba-nos quando nos mostra que não são apenas as políticas transversais e de ações afirmativas que devem se preocupar com a superação do racismo, da LGBTfobia, do machismo, da misoginia, 
do preconceito de classe e das várias formas de violência. Mas que essas devem ser preocupações centrais de uma sociedade diversa e democrática.

Ao ser inserida nas políticas, a diversidade faz com que as políticas públicas brasileiras se tornem cada vez mais públicas. Desnaturaliza as formas violentas, preconceituosas e desiguais como têm sido tratados ao longo dos séculos os coletivos sociais diversos. Faz-nos entender que esses coletivos, constituídos por sujeitos sociais e políticos lutam pelo direito à diferença e pelo seu reconhecimento como sujeitos de direitos. Revela a perversa articulação entre desigualdades sociais, raciais e de gênero.

Entender a urgência das políticas para a diversidade é compreender que direitos iguais significam a presença dos sujeitos diversos em condições de igualdade nos vários lugares, setores e espaços sociais.

As políticas para a diversidade não devem ser vistas como um problema, um incômodo, uma ação de cunho simplesmente partidário ou algo que deva ser calado e invisibilizado. Quando reconhecemos a importância dessas políticas no conjunto das políticas públicas, nos colocamos no cerne da luta por direitos e, dentre estes, o direito à diversidade.

É desafiador, mas não é impossível. Em tempos de uma retomada neoconservadora, fundamentalista e de retrocessos de direitos em nosso país, garantir as políticas de diversidade existentes, ampliá-las e aperfeiçoá-las não é só uma tarefa dos governos. Continua sendo da sociedade como um todo, principalmente daquelas e daqueles que lutam por emancipação social, reconhecimento da diferença, igualdade social, justiça social e cognitiva.

O momento de retrocesso dos direitos democráticos e de crise política pelos quais passa o Brasil deve ser enfrentado. Não podemos desistir da democracia. É preciso olhar para as políticas públicas para a diversidade realizadas nos últimos anos, devido à pressão dos movimentos sociais e outros setores emancipatórios da sociedade civil e resultante das lutas contra-hegemônicas no mundo, entendendo-as como dever do Estado e direito das cidadãs e cidadãos.

Concluiremos, então, que a reação neoconservadora, os ataques da direita e do capital econômico contra essas políticas e os seus sujeitos exigem como resposta o adensamento e a radicalidade da democracia. E para isso é preciso ter coragem. Nos dizeres de Guimarães Rosa:

O correr da vida embrulha tudo. A vida é assim: esquenta e esfria, aperta e dai afrouxa, sossega e depois desinquieta. O que ela quer da gente é coragem. 


\section{REFERÊNCIAS}

EVANS, Peter; RUESCHEMEYER, D; SKOCPOL, Theda. Bringing the State Back. Cambridge: Cambridge University Press, 1985.

GOMES, Nilma Lino. Entrevista com Nilma Lino Gomes. Mídia, Misoginia e Golpe. Brasília: FAC, UnB, 2016, p. 237-241.

SANTOS, Boaventura de Sousa. Para além do pensamento abissal: das linhas globais a uma ecologia de saberes. In: SANTOS, B. S.; MENESES, M. P. (Org). Epistemologias do Sul. Coimbra: Almedina; CES, 2009, p. 23-71.

SOUZA, Celina. Políticas públicas: uma revisão da literatura. Sociologias. Porto Alegre, ano $8, \mathrm{n}^{\mathrm{o}} 16$, jul/dez 2006, p. 20-45. 